\title{
Prevalência dos acidentes de trânsito no estado de Rondônia, entre 2001 e 2013
}

\section{Prevalence of traffic accidents in Rondônia state, 2001 - 2013}

\author{
Carlos Henrique de Sant'Ana Barros ${ }^{1}$, Vinicius Tadeu Ramos da Silva Grillo ${ }^{2}$, Horacio Tamada ${ }^{3}$
}

1. Discente do Curso de Medicina da Universidade Federal de Rondônia (UNIR), Brasil. 2. Médico Residente do Serviço de Cirurgia Geral da Faculdade de Medicina de Botucatu/UNESP, Brasil - orcid.org/0000-0001-9091-0224. 3. Docente do Departamento de Medicina da Universidade Federal de Rondônia (UNIR), Brasil.

\section{Resumo}

Objetivo: Analisar a prevalência de acidentes de trânsito (AT) no estado de Rondônia e na capital Porto Velho com a influência do Complexo Hidroelétrico Madeira aliado ao impacto do decreto da "Lei Seca". Metodologia: 0 estudo é retrospectivo, descritivo, sobre AT que ocorreram entre 2001 e 2013 em Rondônia e em Porto Velho. Os dados foram obtidos nos Anuários Estatísticos do DETRAN-RO. Os dados de mortalidade foram obtidos no Sistema de Informações sobre Mortalidade - DATASUS. Foi realizada revisão bibliográfica nos bancos de dados CAPES e Scielo com os descritores 'acidentes de trânsito', 'mortalidade' e 'direção e álcool'. Resultados: No período entre 2001 e 2013, houve aumento de $201 \%$ na taxa de mortalidade em Rondônia. A frota de veículos aumentou 297\%. Foram 4.849 vítimas fatais. Em Porto Velho, a taxa de mortalidade aumentou 155\% entre 2001 e 2008 . Encerrou-se o período estudado com crescimento de 1,25\%. Entre 2001 e 2013, a frota aumentou 342,7\%. Foram 1.161 vítimas fatais. As faixas etárias entre 18 e 29 anos e entre 30 e 59 anos compuseram o número de vítimas fatais mais frequentes. Conclusão: A educação é o passo inicial para a mudança dos hábitos da população, condição necessária para que o número de AT seja reduzido.

Palavras-chave: Acidentes de trânsito. Motocicletas. “Lei Seca”. Álcool. Violência no trânsito. Mortalidade.

\begin{abstract}
Objective: Analyze the prevalence of traffic accidents at Rondonia state and the capital Porto Velho taking into account the influency of Madeira Hydroeletric Complex allied to the impact of the "Lei Seca" decree. Metodology: This is a retrospective and descriptive study about the traffic injuries that occurred between 2001-2013 in Rondônia and in Porto Velho. The data sources about traffic accidents were obtained from the Mortality Information System DATASUS. A bibliographic review at CAPES and Scielo data base with the descriptors 'traffic accidents', 'mortality', 'driving and alcohol' were carried out. Results: In the period from 2001 to 2013, there was an increase of 201\% in the mortality rate in Rondônia. The fleet of vehicles raised 297\%. There happened 4. 849 fatal victims. At Porto Velho, the mortality rate increased 155\% from 2001 to 2008 . The period studied ended with an increase of 1,25\%. Between 2001 to 2013, the number of vehicles had an increase of 342,7\%. Fatal victims were 1.161. Most victims belonged to the age group from 18 to 29 years old and from 30 to 59 years old. Conclusion: Education is the first step to be taken in order to achieve change of habits, which is an absolute must in order to decrease traffic injuries.
\end{abstract}

Keywords: Traffic injuries. Motor-cycles. "Lei Seca". Alcohol. Traffic violence. Mortality.

\section{INTRODUÇÃO}

No aspecto de pesquisa em saúde coletiva, os acidentes de trânsito (AT) são considerados, teoricamente, uma causa prevenível. Além disso, é importante ressaltar que não ocorrem aleatoriamente e têm como fatores de risco a situação das vias, a condição dos veículos e o comportamento de pedestres, ciclistas ou condutores. Assim, as altas taxas de AT expõem uma relação conflitante entre a implementação de políticas públicas de controle e a prevenção de acidentes e a educação no trânsito segundo o código de trânsito de 1998, com a alta tecnologia desenvolvida para conferir maior segurança aos veículos, com a inserção de radares eletrônicos para controle de velocidade nas vias e com o ofício dos fiscais de trânsito, visto que não se tem observado redução estatisticamente significante do número de óbitos ${ }^{1,2,3}$.

De acordo com o banco de dados de mortalidade do País, no período de 2001 a 2013, foram registrados 1 milhão e 756 mil óbitos por causas externas e, destes, 490 mil devem-se aos acidentes de transporte terrestre. No estado de Rondônia foram registrados 18.208 óbitos por causas externas nesse mesmo período, sendo 5.810 devido a acidentes de transporte terrestre ${ }^{4}$.

O estado foi classificado pelo Mapa da Violência como a segunda Unidade Federativa que mais registra AT no país no ano de $2013^{5}$. Um fator importante que está relacionado a esse aumento é o advento do Complexo Hidrelétrico do Madeira, composto pelas Usinas Hidroelétricas de Jirau e Santo Antônio, cujo canteiro de obras atraiu um grande contingente de trabalhadores, elevando o poder aquisitivo da população, o que resultou diretamente no aumento da frota e em maior incidência de acidentes. Porto Velho, capital do estado, acompanhou o movimento migratório 
ocasionado pelo Complexo Hidrelétrico do Madeira, registrando 5.903 óbitos por causas externas nesse período, sendo 1.668 devido a acidentes de transporte terrestre ${ }^{6}$.

Como medida de prevenção e redução do número de $\mathrm{AT}$, o governo federal, por meio da Lei 11.705/2008, conhecida como "Lei Seca", alterou o Código de Trânsito Brasileiro estabelecendo índice de alcoolemia zero e impondo penalidade severa ao condutor que dirigir sob a influência de álcool, infração que resulta em multa e suspensão do direito de dirigir por 12 meses, além da retenção do veículo e recolhimento da habilitação, conforme o Art. 165 do código. Nesse sentido, o DETRAN-RO tem realizado atividades educativas por meio da campanha da Semana Nacional de Trânsito.

Devido à grande importância do estudo da mortalidade no trânsito, o presente trabalho tem por objetivo analisar a prevalência de AT no estado de Rondônia e na capital Porto Velho, no período de 2001 a 2013.

\section{METODOLOGIA}

O estudo é de base populacional, retrospectivo, descritivo, tratando dos AT que ocorreram entre os anos de 2001 a 2013 no estado de Rondônia. Foi realizada revisão bibliográfica nos bancos de dados CAPES e Scielo com os descritores 'acidentes de trânsito', 'mortalidade' e 'direção e álcool', além de pesquisa no sitio eletrônico do Ministério da Saúde para obtenção de dados sobre mortalidade por causas externas e no sítio eletrônico do Governo Federal acerca das Leis 11.705 e 12.760.

As informações e dados apresentados neste estudo provêem de registros feitos na Delegacia Especializada em Delitos de Trânsito, batalhões da Polícia Militar, Instituto Médico Legal e Polícia Rodoviária Federal, sendo estes dados de domínio público, disponíveis nos Anuários Estatísticos do DETRANRO. Os dados de mortalidade foram obtidos no Sistema de Informações sobre Mortalidade ${ }^{6}$. Foram considerados AT todos os eventos ocorridos em via pública, abrangendo colisões entre os variados tipos de veículos motorizados, atropelamentos, colisões entre ciclistas e pedestres, tombamentos, capotagem e choques contra objetos fixos.

Procedeu-se a análise dos bancos de dados do Registro Nacional de Acidentes e Estatísticas de Trânsito - RENAEST, unidade do Departamento Estadual de Trânsito de Rondônia - DETRAN, Departamento Nacional de Trânsito - DENATRAN e, do Mapa da Violência do ano de 2013 do Centro Brasileiro de Estudos Latino-Americanos com busca ativa sobre acidentes com vítimas, vítimas fatais, atropelamentos, índice de acidentes com vítimas por 10.000 veículos, índice de acidentes com vítimas por 100.000 habitantes, índice de vítimas fatais e não fatais por 10.000 veículos, índice de vítimas fatais e não fatais por 100.000 habitantes, acidentes com vítimas fatais e não fatais segundo sexo, acidentes com vítimas fatais e não fatais segundo faixa etária, acidentes com vítimas fatais e não fatais segundo o tipo de veículo, acidentes com condutores segundo habilitação e faixa etária, frota, período.
O estado de Rondônia está localizado na Região Norte, e tem como limites os estados do Mato Grosso, Amazonas, Acre e a República da Bolívia. É cortado por 24 mil km de malha viária. As estradas pavimentadas alcançam somente 7\%. A BR-364, totalmente pavimentada no trecho rondoniense, é a principal via de escoamento da produção de grãos do Sul do estado e oeste do Mato Grosso até a capital Porto Velho, onde está instalado o porto graneleiro. Além disso, é por meio dela que ocorre o abastecimento de alimentos, medicamentos, materiais de construção, entre outros itens para o estado do Acre.

Para permitir adequada análise e comparação entre os anos, a taxa de mortalidade por acidentes foi calculada pela mortalidade proporcional por grupos de causa, a qual é dada pela seguinte fórmula:

Óbitos residentes por grupo de causas definidas $x 100$

$\bar{N}$ o total de óbitos residentes - Óbitos por causas mal definidas

e pelo coeficiente de mortalidade específica por causas externas, cuja fórmula é:

$$
\frac{\text { Óbitos residentes por causas externas }}{\text { População total residente ajustada ao meio do ano }} \times 100.000
$$

O índice populacional utilizado é o fornecido pelos dados dos anuários estatísticos do DETRAN para o período estudado. A variação proporcional percentual (VPP) foi calculada para demonstrar a magnitude da variação no período estudado, de acordo com a seguinte fórmula:

$$
V P P=\frac{(\text { ano 2013 })-(\text { ano 2001) } \times 100}{\text { ano } 2001}
$$

Foi constituído banco de dados no programa Excel 2010, no qual foram feitas as análises e construídos os gráficos. O presente estudo não foi submetido à avaliação do Sistema CEP-CONEP por razão de consistir de pesquisa em arquivos de instituições públicas, bancos de dados secundários e dados de domínio público que não identificam os participantes, além de revisão bibliográfica.

\section{RESULTADOS}

\section{Dados do período entre 2001 e 2013}

\section{Rondônia}

Os AT no estado de Rondônia são responsáveis por 7,78\% da mortalidade proporcional por grupos de causas. Em 2001, a taxa de mortalidade foi de 9,3 óbitos a cada 100.000 habitantes, número que em 2013 passou para 28,1 óbitos, valor que representa aumento percentual de $201 \%$. O coeficiente de mortalidade específica por causas externas corresponde a 1.053,6 óbitos para cada 100.000 habitantes no período estudado. A população do estado de Rondônia, no ano de 2013, era de 1.728.214 habitantes. O crescimento populacional 
percentual observado no período estudado foi de $22,75 \%$.

A frota total de veículos aumentou progressivamente, saltando de 190.719 veículos em 2001 para 757.208 veículos em 2013, correspondendo a uma VPP de $297 \%$ (figura 1). Automóveis e camionetas respondiam por 76.131 dos veículos em 2001. Entre 2009 e 2010, duplicou a quantidade de veículos dessas categorias; entre 2011 e 2012, foi observado o período de maior crescimento percentual, $16,5 \%$, finalizando o ano de 2013 com 239.299 veículos, número que representa 31,6\% da frota desse ano para o estado, com VPP de $214,3 \%$. O número de motocicletas em 2001 era de 89.840, dobrando esse número entre os anos de 2007 e 2008, coincidindo com o período de maior crescimento percentual observado, $19,3 \%$. Em 2013 foram registrados 410.726 veículos dessa categoria, o que corresponde a $54,2 \%$ da frota para o referido ano, com VPP de 357\%. O número de caminhões em 2001 era de 12.297, dobrando entre 2011 e 2012, encerrando 2013 com 26.702 veículos, representando $3,52 \%$ da frota do ano, com VPP de $117 \%$.

Figura 1. Evolução da frota de veículos no estado de Rondônia, período de 2001 a 2013.

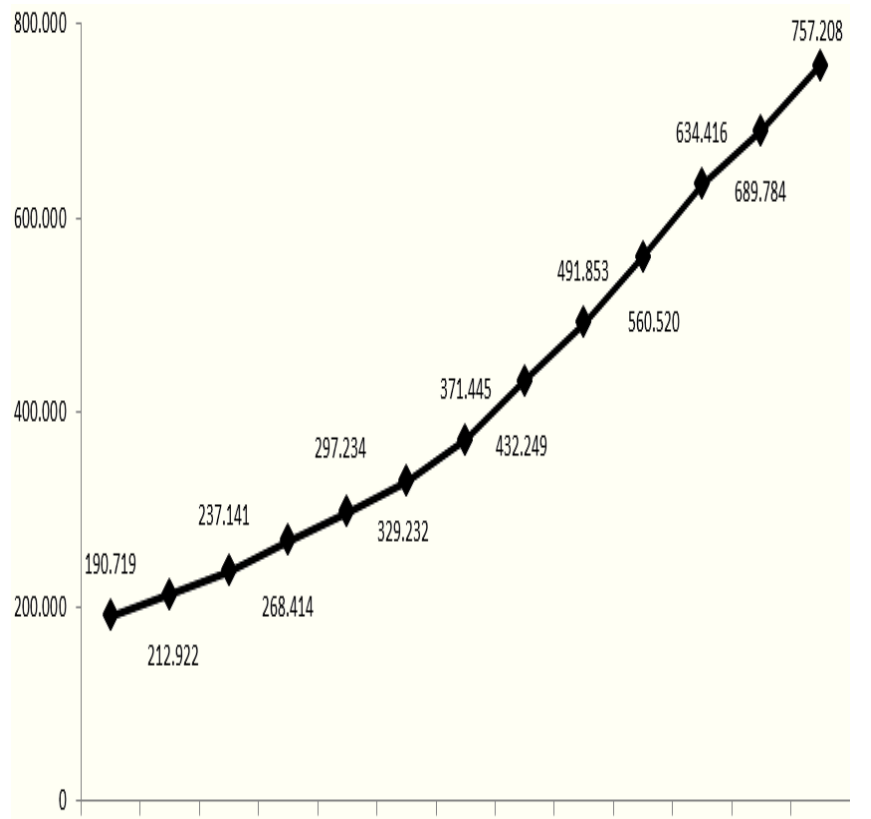

$200120022003200420052006200720082009201020112012 \quad 2013$

Entre os anos 2001 e 2013, ocorreram 108.739 AT. Em 2001, o número registrado de vítimas por AT foi 2.062, elevando-se para 3.151 em 2002, 52,8\% de aumento percentual para o biênio. No entanto, entre 2006 e 2007, houve registro de aumento de 4.599 para $7.984(73,6 \%)$ acidentes com vítimas. A maior redução observada no período ocorreu entre 2012 e 2013, com decréscimo de 14.449 para 13.759 (4,78\%) acidentes com vítimas.

Em relação aos atropelamentos, houve um aumento progressivo em sua incidência durante o período, totalizando 10.139 eventos. A comparação entre os anos de 2001 e 2002 mostra aumento de $55,4 \%$ no número de atropelamentos, sendo que entre 2006 a 2011 houve crescimento progressivo com discreto decréscimo entre 2012 e 2013 (figura 2). A VPP para o período correspondeu a $343,5 \%$.

Figura 2. Evolução do número de atropelamentos no estado de Rondônia entre 2001 a 2013

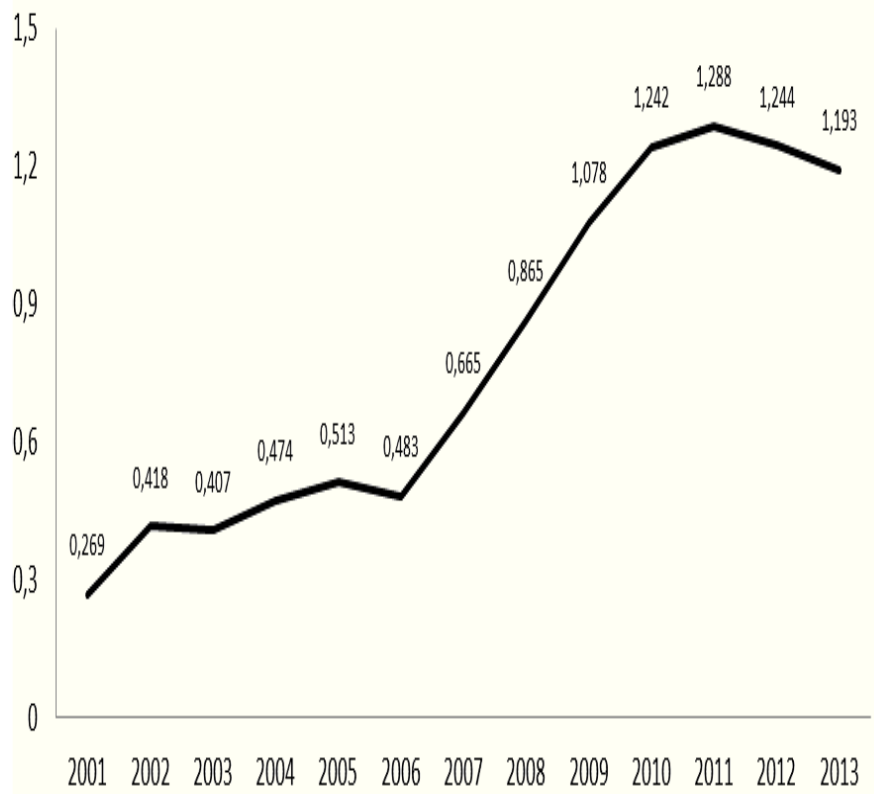

Quanto à ocorrência de AT segundo a fase do dia, 62\% (67.411) dos acidentes ocorreram durante o dia, 36,2\% (39.404) ocorreram à noite e 1,8\% não informados. Em relação à zona de ocorrência, 77,9\% (84.703) ocorreram em zona urbana, 13,9\% (15.125) em zona rural e 8,2\% não informados.

O número total de veículos envolvidos em AT com vítimas foi de 194.564 , sendo que $47,7 \%$ eram motocicletas, $30,1 \%$ automóveis ou camionetas, $8,4 \%$ bicicletas, $7,4 \%$ caminhões ou caminhonetes, $1,5 \%$ ônibus ou micro-ônibus, $0,5 \%$ reboque ou semirreboque, $0,8 \%$ outros e $3,6 \%$ não informados.

A análise da condição dos condutores envolvidos em acidentes segundo a habilitação mostra que $63,9 \%$ estavam habilitados, $9 \%$ inabilitados, 3,5\% permissionados, $4 \%$ eram condutores de veículo cuja habilitação não é exigível e 19,6\% não tiveram sua condição informada. Em relação à idade dos condutores, $42,3 \%$ (82.305) estão na faixa etária entre 30 a 59 anos, 35,6\% (69.206) estão entre 18 a 29 anos, 3,8\% (7.442) estão na faixa etária de 60 anos ou mais, 2,6\% (5.123) são menores de 18 anos e $15,7 \%$ não informados.

\section{Porto Velho}

Na capital do estado de Rondônia, os AT respondem por 6,53\% da mortalidade proporcional por grupos de causas. A taxa de mortalidade em 2001 era de 13,4 óbitos em 100.000 habitantes, sendo que esse índice passou a ser de 34,3 óbitos em 2008, diminuindo para 13,6 óbitos em 2013, o que representa VPP de 
$155 \%$ e $1,25 \%$, com relação aos respectivos anos. O coeficiente de mortalidade específica por causas externas corresponde a $1.217,1$ óbitos por 100.000 habitantes no período estudado.

O crescimento populacional para o período foi de $41,7 \%$. A frota cresceu $342,7 \%$, de acordo com dados do DENATRAN ${ }^{7}$, cujo número de veículos era de 50.192 em 2001, passando a ser 222.218 em 2013. O número de automóveis e camionetas era de 33.186 em 2001. Esse valor dobrou entre 2009 e 2010 sendo que o crescimento percentual do biênio foi de $16,4 \%$. Essa categoria registrou 97.379 veículos ao final de 2013, representando, assim, 43,8\% da frota total nesse ano. O VPP é de 1,93\% para essa categoria. O número de motocicletas era de 10.553 em 2001, dobrando entre 2005 e 2006. Em 2009 houve o maior crescimento percentual observado para essa categoria, $29,3 \%$. Nesse mesmo ano, a frota de motocicletas duplicou em relação a 2001, sofrendo nova duplicação em 2012, finalizando 2013 com 86.826 motocicletas na capital, o que representa $39 \%$ da frota total do ano, cujo VPP foi de $7,2 \%$.

No período estudado, ocorreram 38.318 AT com vítimas, sendo 56.317 o número total de vítimas fatais e não fatais. Entre os anos de 2006 e 2007, foi registrado o maior aumento percentual no número de AT com vítimas, cujo valor ascendeu de 1.260 para 2.821 , representando aumento de $124 \%$. O maior valor absoluto em número de acidentes observado foi de $5.356 \mathrm{em}$ 2011, evoluindo com redução de $8,6 \%$ em relação ao ano de 2013.

O número de atropelamentos registrados entre 2001 e 2013 foi de 3.245 eventos. Entre 2006 e 2007, houve aumento de 110 para 207 ocorrências, cujo aumento percentual é de 88,2\%, o maior observado para o período. O número de registros em 2013 foi de 438 ocorrências. A VPP para o período foi de $301,8 \%$.

A análise dos AT quanto à fase do dia mostra que $61,4 \%$ (23.508) dos acidentes ocorreram durante o dia, 36,5\% (13.978) ocorreram à noite e 2,1\% não informados. Quanto à zona de ocorrência, $97,2 \%$ dos AT foram registrados na zona urbana, $1,8 \%$ em zona rural e 1,1\% não informados.
O número de veículos envolvidos em acidentes com vítimas foi de 72.618 , sendo $42,1 \%$ motocicletas, $35,7 \%$ automóveis ou camionetas, 9,7\% bicicletas, $4,8 \%$ caminhão ou caminhonete, $1,8 \%$ ônibus ou micro-ônibus, $0,8 \%$ outros, $0,3 \%$ semirreboque ou reboque e $4,7 \%$ não informados.

Quanto à condição do condutor segundo a habilitação, 60,1\% eram habilitados, $6,8 \%$ inabilitados, 3,4\% permissionados, $4,1 \%$ eram condutores de veículos cuja habilitação não é exigível, $25,6 \%$ não informados. Quanto à idade dos condutores, $41,6 \%$ (30.221) estão na faixa etária de 30 a 59 anos, 33,2\% (24.074) estão entre 18 a 29 anos, 2,9\% (2.070) estão entre 60 ou mais anos, 2,5\% (1.781) são menores de 18 anos e 19,9\% não informados.

\section{VIITIMAS FATAIS}

\section{Rondônia}

O número de vítimas fatais por AT entre 2001 e 2013 foi de 4.849 indivíduos, o que corresponde a 2,9\% do número absoluto de vítimas. Entre 2001, houve registro de 131 vítimas fatais. Em 2004, foi observado o maior aumento percentual do período $88,42 \%$-, elevando o número de vítimas fatais de 190 para 358 em relação ao ano anterior. A maior elevação no número de vítimas fatais ocorreu em 2012, alcançando 611 indivíduos. Em 2013, houve queda para 484 vítimas, com redução de 20,79\%.

A análise comparativa entre os sexos mostra que $77 \%$ das vítimas fatais são do sexo masculino, enquanto $22 \%$ são do sexo feminino, o que corresponde a 4:1 óbitos. Em 1\% dos registros não foi informado o sexo dos indivíduos.

Os indivíduos na faixa etária entre 18 a 29 anos e entre 30 a 59 anos foram as vítimas fatais mais frequentes, cuja soma totaliza 2.876 vítimas entre 2001 a 2013, o que corresponde a $59,3 \%$ do total de vítimas fatais segundo faixa etária. Crianças e adolescentes, juntos, constituem $15,9 \%$ das vítimas fatais no período, enquanto que os idosos e indivíduos com idade não informada correspondem a 9,9\%. 14,9\% das vítimas fatais não tiveram sua faixa etária informada (tabela 1).

Tabela 1. Acidentes com vítimas fatais no estado de Rondônia segundo faixa etária, período entre 2001 e 2013.

\begin{tabular}{lrrrrrrrrrrrrrr}
\hline & \multicolumn{10}{c}{ Período } \\
\cline { 2 - 12 } & $\mathbf{2 0 0 1}$ & $\mathbf{2 0 0 2}$ & $\mathbf{2 0 0 3}$ & $\mathbf{2 0 0 4}$ & $\mathbf{2 0 0 5}$ & $\mathbf{2 0 0 6}$ & $\mathbf{2 0 0 7}$ & $\mathbf{2 0 0 8}$ & $\mathbf{2 0 0 9}$ & $\mathbf{2 0 1 0}$ & $\mathbf{2 0 1 1}$ & $\mathbf{2 0 1 2}$ & $\mathbf{2 0 1 3}$ & Total \\
\hline 0 a 9 anos & 8 & 9 & 6 & 15 & 14 & 11 & 2 & 15 & 10 & 18 & 22 & 20 & 17 & 167 \\
10 a 12 anos & 11 & 15 & 19 & 39 & 15 & 13 & 14 & 11 & 8 & 3 & 3 & 7 & 2 & 160 \\
13 a 17 anos & 23 & 38 & 33 & 59 & 55 & 53 & 50 & 23 & 21 & 21 & 15 & 32 & 22 & 445 \\
18 a 29 anos & 25 & 32 & 32 & 72 & 89 & 77 & 64 & 117 & 121 & 132 & 136 & 162 & 122 & 1181 \\
30 a 59 anos & 17 & 29 & 36 & 86 & 87 & 82 & 88 & 157 & 176 & 218 & 229 & 267 & 223 & 1695 \\
60 anos ou mais & 9 & 10 & 16 & 29 & 28 & 28 & 48 & 43 & 40 & 44 & 43 & 74 & 67 & 479 \\
Não Informado & 38 & 61 & 48 & 58 & 39 & 49 & 98 & 106 & 44 & 48 & 53 & 49 & 31 & 722 \\
Total & 131 & 194 & 190 & 358 & 327 & 313 & 364 & 472 & 420 & 484 & 501 & 611 & 484 & 4849 \\
\hline
\end{tabular}


A análise das vítimas fatais segundo o tipo de categoria mostra que 1.791 condutores, 1.118 passageiros, 572 pedestres, 922 motociclistas, 164 ciclistas e 10 outros faleceram vítimas de AT no período de 2001 a 2013. Não há informações sobre os dados referentes às categorias dos motociclistas e ciclistas entre 2001 e 2008 (tabela 2).

Tabela 2. Acidentes com vítimas fatais segundo condição da vítima no momento do acidente no estado de Rondônia, período entre 2001 e 2013.

\begin{tabular}{|c|c|c|c|c|c|c|c|c|c|c|c|c|c|c|}
\hline \multirow{2}{*}{ Categoria } & \multicolumn{14}{|c|}{ Período } \\
\hline & 2001 & 2002 & 2003 & 2004 & 2005 & 2006 & 2007 & 2008 & 2009 & 2010 & 2011 & 2012 & 2013 & Total \\
\hline Condutor & 76 & 126 & 115 & 178 & 206 & 170 & 198 & 232 & 90 & 109 & 124 & 103 & 64 & 1791 \\
\hline Passageiro & 28 & 36 & 39 & 100 & 74 & 100 & 67 & 101 & 90 & 102 & 120 & 149 & 112 & 1118 \\
\hline Pedestre & 14 & 22 & 28 & 61 & 29 & 34 & 39 & 35 & 56 & 68 & 67 & 64 & 55 & 572 \\
\hline Motociclista & ---- & ---- & ---- & ---- & ---- & ---- & ---- & ---- & 137 & 163 & 159 & 246 & 217 & 922 \\
\hline Ciclista & ---- & ---- & ---- & ---- & ---- & ---- & ---- & ---- & 32 & 33 & 26 & 44 & 29 & 164 \\
\hline Outro & 0 & 0 & 0 & 0 & 0 & 0 & 0 & 4 & 1 & 2 & 1 & 1 & 1 & 10 \\
\hline Não Informado & 13 & 10 & 8 & 19 & 18 & 9 & 60 & 100 & 14 & 7 & 4 & 4 & 6 & 272 \\
\hline Total & 131 & 194 & 190 & 358 & 327 & 313 & 364 & 472 & 420 & 484 & 501 & 611 & 484 & 4849 \\
\hline
\end{tabular}

\section{Porto Velho}

Na capital, houve 1.161 vítimas fatais registradas entre os anos de 2001 a 2013, valor que representa $2 \%$ do número absoluto de vítimas. Em 2001, foram registradas 46 vítimas fatais. Em 2008 foram registradas 130 mortes por AT, o maior número de vítimas observado no período, sendo que esse valor sofreu decréscimo de 50,8\% em 2013, ano que registrou 66 ocorrências.

A análise comparativa entre os sexos mostra que $72,8 \%$ das vítimas são do sexo masculino e $25,8 \%$ do sexo feminino, cuja relação é de aproximadamente 3:1 óbitos. Não houve informação sobre o sexo em $1,4 \%$ dos registros.

Com relação à faixa etária das vítimas fatais, indivíduos entre 18 e 29 anos e entre 30 e 59 anos correspondem a 648 (55,8\%) vitimas, crianças e adolescentes somam 195 (16,8\%) vítimas, idosos contabilizam 119 (10,2\%) vítimas e 199 (17,1\%) indivíduos não tiveram sua faixa etária categorizada (tabela 3).

Tabela 3. Acidentes com vítimas fatais em Porto Velho/RO segundo faixa etária, período entre 2001 e 2013.

\begin{tabular}{lrrrrrrrrrrrrrr}
\hline & \multicolumn{10}{c}{ Período } \\
\cline { 2 - 3 } Faixa Etária & $\mathbf{2 0 0 1}$ & $\mathbf{2 0 0 2}$ & $\mathbf{2 0 0 3}$ & $\mathbf{2 0 0 4}$ & $\mathbf{2 0 0 5}$ & $\mathbf{2 0 0 6}$ & $\mathbf{2 0 0 7}$ & $\mathbf{2 0 0 8}$ & $\mathbf{2 0 0 9}$ & $\mathbf{2 0 1 0}$ & $\mathbf{2 0 1 1}$ & $\mathbf{2 0 1 2}$ & $\mathbf{2 0 1 3}$ & Total \\
\hline 0 a 9 anos & 0 & 0 & 2 & 5 & 5 & 4 & 0 & 3 & 2 & 4 & 2 & 4 & 3 & 34 \\
10 a 12 anos & 3 & 7 & 5 & 8 & 8 & 8 & 3 & 3 & 2 & 0 & 0 & 1 & 0 & 48 \\
13 a 17 anos & 7 & 13 & 8 & 10 & 22 & 10 & 17 & 6 & 1 & 8 & 4 & 5 & 2 & 113 \\
18 a 29 anos & 9 & 9 & 13 & 13 & 25 & 41 & 21 & 22 & 31 & 29 & 31 & 25 & 18 & 287 \\
30 a 59 anos & 5 & 9 & 10 & 10 & 20 & 26 & 38 & 37 & 40 & 56 & 37 & 46 & 27 & 361 \\
60 anos ou mais & 3 & 5 & 5 & 6 & 5 & 8 & 16 & 17 & 10 & 13 & 10 & 12 & 9 & 119 \\
Não Informado & 19 & 17 & 28 & 28 & 5 & 8 & 13 & 42 & 7 & 6 & 9 & 10 & 7 & 199 \\
Total & 46 & 60 & 71 & 80 & 90 & 105 & 108 & 130 & 93 & 116 & 93 & 103 & 66 & 1161 \\
\hline
\end{tabular}

A análise das vítimas fatais segundo o tipo de categoria mostra que 376 condutores, 194 passageiros, 198 pedestres, 209 motociclistas, 57 ciclistas e 1 outro faleceram vítimas de AT no período de 2001 a 2013. Não há informações sobre os dados referentes às categorias dos motociclistas e ciclistas entre 2001 e 2008 (tabela 4). 
Tabela 4. Acidentes com vítimas fatais segundo a condição da vítima no momento do acidente em Porto Velho/RO, período entre 2001 e 2013.

\begin{tabular}{|c|c|c|c|c|c|c|c|c|c|c|c|c|c|c|}
\hline \multirow{2}{*}{ Categoria } & \multicolumn{13}{|c|}{ Período } & \multirow[b]{2}{*}{ Total } \\
\hline & 2001 & 2002 & 2003 & 2004 & 2005 & 2006 & 2007 & 2008 & 2009 & 2010 & 2011 & 2012 & 2013 & \\
\hline Condutor & 32 & 36 & 46 & 40 & 52 & 57 & 48 & 47 & 5 & 5 & 6 & 1 & 1 & 376 \\
\hline Passageiro & 6 & 8 & 7 & 22 & 19 & 27 & 14 & 13 & 16 & 11 & 17 & 25 & 9 & 194 \\
\hline Pedestre & 5 & 12 & 16 & 16 & 9 & 20 & 12 & 10 & 17 & 29 & 22 & 18 & 12 & 198 \\
\hline Motociclista & ---- & ---- & ---- & ---- & ---- & ---- & ---- & ---- & 38 & 53 & 40 & 44 & 34 & 209 \\
\hline Ciclista & ---- & ---- & ---- & ---- & ---- & ---- & ---- & ---- & 13 & 15 & 7 & 12 & 10 & 57 \\
\hline Outro & 0 & 0 & 0 & 0 & 0 & 0 & 0 & 0 & 0 & 1 & 0 & 0 & 0 & 1 \\
\hline Não Informado & 3 & 4 & 2 & 2 & 10 & 1 & 34 & 60 & 4 & 2 & 1 & 3 & 0 & 126 \\
\hline Total & 46 & 60 & 71 & 80 & 90 & 105 & 108 & 130 & 93 & 116 & 93 & 103 & 66 & 1161 \\
\hline
\end{tabular}

\section{VÍTIMAS NÃO FATAIS}

\section{Rondônia}

O número de vítimas não fatais por AT correspondeu a 159.632 no período de 2001 a 2013. Entre 2001 e 2002, houve crescimento de $56,6 \%$ no número de vítimas não fatais. O maior aumento percentual observado foi de $72,6 \%$ e ocorreu entre os anos de 2006 (6.668) e 2007 (11.509), que coincide com o intervalo de maior aumento percentual observado no número de AT com vítimas. Entre 2012 (21.408) e 2013 (20.357), houve decréscimo de $4,9 \%$ das vítimas não fatais.

A evolução dos acidentes com vítimas não fatais segundo sexo durante os 13 anos analisados mostra um total de $67,6 \%$ vítimas do sexo masculino e $28 \%$ vítimas do sexo feminino. A categoria "sexo" não foi informada por 4,4\% das vítimas não fatais.

As faixas etárias entre 18 e 29 anos e entre 30 a 59 anos respondem por $34,1 \%$ e $31,5 \%$ das vítimas não fatais, respectivamente. Crianças e adolescentes representam 16,6\% das vítimas não fatais, enquanto os idosos correspondem à menor parcela, com $0,8 \%$ de vítimas não fatais. Ignorados e não informados somam $13,4 \%$.

Quanto à condição das vítimas não fatais no momento do acidente segundo a categoria, foram observados 53.629 condutores, 35.007 passageiros, 8.196 pedestres, 50.725 motociclistas, 6.605 ciclistas, 205 outros e 4.265 não informados.

\section{Porto Velho}

O número de vítimas não fatais registrado na capital entre os anos de 2001 e 2013 foi de 55.156. Em 2001, foram observadas 1.221 vítimas de AT. O número de ocorrências aumentou progressivamente ao longo dos anos até atingir sua maior incidência em 2011, registrando 7.938 vítimas não fatais. Em 2013 , esse número reduziu-se em $8,2 \%$, encerrando o ano com 7.287 vítimas.

A análise comparativa entre os sexos das vítimas mostra que
$65,5 \%$ (36.134) pertenciam ao sexo masculino e $27,8 \%$ (15.322) ao sexo feminino e $6,7 \%$ dos indivíduos não informaram o sexo.

As faixas etárias entre 18 e 29 anos e entre 30 a 59 anos, somadas, respondem por $69 \%$ (38.050) do total de vitimas não fatais. Crianças e adolescentes representam 11,3\% (6.242) e os idosos 2,4\% (1.341) das vítimas não fatais. Eventos ignorados e não informados correspondem a 17,3\% (9.519).

Quanto à condição das vítimas não fatais no momento do acidente segundo categoria, foram observados 17.893 condutores, 10.850 passageiros, 2.906 pedestres, 18.972 motociclistas, 2.924 ciclistas, 42 outros e 1.569 não informados.

\section{ÍNDICES}

\section{Rondônia}

O índice de motorização (número de veículos por 100 habitantes) foi 13,5 em 2001, crescendo progressivamente até 2012, quando registrou 43,9, com decréscimo para 43,8, em 2013.

O índice de acidentes com vítimas por 10.000 veículos foi de 108,2 em 2001. Em 2009, o índice alcançou 249,1, finalizando o ano de 2013 em 169,4. Já o índice de acidentes com vítimas por 100.000 habitantes foi de 146,6 em 2001, com crescimento até o ano de 2011, quando alcançou o número de 932,8, finalizando o ano de 2013 com o indicativo de 796,1 acidentes com vítimas por 100.000 habitantes.

O índice de vítimas fatais por 10.000 veículos era de 6,9 vítimas em 2001, atingindo o valor de 13,3 vítimas em 2004, com decréscimo para 6,4 vítimas em 2013. Já o índice de vítimas fatais por 100.000 habitantes era de 9,3 vítimas em 2001, passando para 31,6 em 2008, com pequena oscilação até 2012, ano em que atingiu o valor de 38,4 vítimas, decrescendo para 
28 vítimas por 100.000 habitantes em 2013.

O índice de vítimas não fatais por 10.000 veículos foi de 143,4 em 2001, elevando-se para 372 em 2009, finalizando o ano de 2013 registrando o indicativo de 268,8 . Já o índice de vítimas não fatais por 100.000 habitantes registrou 194,3 acidentes em 2001, elevando-se progressivamente até o ano de 2011, cujo valor foi de 1381,7 acidentes, finalizando o ano de 2013 com o valor de 1177,9 acidentes.

Tabela 5. Índices do estado de Rondônia, período entre 2001 e 2013.

\begin{tabular}{|c|c|c|c|c|c|c|c|c|c|c|c|c|c|}
\hline \multirow[b]{2}{*}{ Categoria } & \multicolumn{13}{|c|}{ Período } \\
\hline & 2001 & 2002 & 2003 & 2004 & 2005 & 2006 & 2007 & 2008 & 2009 & 2010 & 2011 & 2012 & 2013 \\
\hline \multicolumn{14}{|l|}{ Motorização (Veíc./ 100} \\
\hline hab) & 13,5 & 14,9 & 16,3 & 17,2 & 19,4 & 21,1 & 25,6 & 28,9 & 32,7 & 36,5 & 40,2 & 43,9 & 43,8 \\
\hline \multicolumn{14}{|l|}{ Acid. c/ vít./10.000 } \\
\hline veículos & 108,2 & 157,4 & 132,6 & 161,7 & 158,3 & 139,7 & 214,9 & 230 & 249,1 & 243,5 & 231,8 & 207,5 & 169,4 \\
\hline \multicolumn{14}{|l|}{ Acid. c/ vít/ } \\
\hline 100.000 habitantes & 277 & 341,8 & 378 & 338,2 & 404,9 & 330,7 & 763,8 & 889,3 & 1134,2 & 1229,4 & 1229,2 & 1117,5 & 1009,5 \\
\hline \multicolumn{14}{|l|}{100.000 habitantes } \\
\hline & 146,6 & 234,1 & 215,9 & 277,9 & 306,5 & 294,4 & 549,2 & 665,6 & 814,8 & 888,6 & 932,8 & 911,9 & 796,1 \\
\hline \multicolumn{14}{|l|}{ Vít. fatais / 10.000} \\
\hline veículos & 6,9 & 9,1 & 8 & 13,3 & 11 & 9,5 & 9,8 & 10,9 & 8,5 & 8,6 & 7,9 & 8,7 & 6,4 \\
\hline \multicolumn{14}{|l|}{ Vít. fatais / 100.000} \\
\hline habitantes & 9,3 & 13,5 & 13,1 & 22,9 & 21,3 & 20 & 25 & 31,6 & 27,9 & 31,5 & 31,8 & 38,4 & 28 \\
\hline \multicolumn{14}{|l|}{ Vít. não fatais / 10.000} \\
\hline veículos & 143,4 & 201,2 & 174,8 & 226,3 & 216,9 & 202,5 & 310,1 & 336,5 & 372 & 363,5 & 343,3 & 306,4 & 268,8 \\
\hline \multicolumn{14}{|l|}{ Vít. não fatais / 100.000} \\
\hline habitantes & 194,3 & 299,3 & 284,8 & 388,8 & 420 & 426,8 & 792,4 & 973,9 & 1216,7 & 1327 & 1381,7 & 1346,4 & 1177,9 \\
\hline
\end{tabular}

\section{Porto Velho}

O índice de motorização (número de veículos por 100 habitantes) foi 14,7 em 2001, crescendo progressivamente até 2012, quando registrou 46,8, com decréscimo para 45,8, em 2013.

O índice de acidentes com vítimas por 10.000 veículos foi de 188,9 em 2001. Em 2009, o índice alcançou 320,6, finalizando o ano de 2013 em 220,6. Já o índice de acidentes com vítimas por 100.000 habitantes foi de 277 em 2001, com grande crescimento no ano de 2007, alcançando o valor de 1229,4 em 2010, finalizando o ano de 2013 com 1009,5.

O índice de vítimas fatais por 10.000 veículos foi de 9,6 vítimas em 2001, atingindo o valor de 12,2 vítimas em 2006, com decréscimo para três vítimas em 2013. Já o índice de vítimas fatais por 100.000 habitantes era de 14 vítimas em 2001, passando para 34,3 em 2008, decrescendo para 13,6 vítimas em 2013.

O índice de vítimas não fatais por 10.000 veículos foi de 243,4 em 2001, elevando-se para 472,1 em 2009, encerrando 2013 com 328,4 . Já o índice de vítimas não fatais por 100.000 registrou 356,7 acidentes em 2001, elevando-se para 1156,6 em 2007, atingindo o valor de 1827,2, em 2010 acidentes, encerando 2013 com o valor de 1502,5 acidentes. 
51 Acidentes de trânsito em Rondônia entre 2001 e 2013

Tabela 6. Índices de Porto Velho/RO, período entre 2001 e 2013

\begin{tabular}{|c|c|c|c|c|c|c|c|c|c|c|c|c|c|}
\hline \multirow{2}{*}{ Categoria } & \multicolumn{13}{|c|}{ Período } \\
\hline & 2001 & 2002 & 2003 & 2004 & 2005 & 2006 & 2007 & 2008 & 2009 & 2010 & 2011 & 2012 & 2013 \\
\hline $\begin{array}{l}\text { Motorização (Veíc./ } 100 \\
\text { hab) }\end{array}$ & 14,7 & 16,1 & 17,4 & 18,2 & 20,6 & 22,6 & 26,3 & 30,1 & 35,4 & 39,2 & 43,1 & 46,8 & 45,8 \\
\hline $\begin{array}{l}\text { Acid. c/ vít./10.000 } \\
\text { veículos }\end{array}$ & 188,9 & 212,1 & 216,8 & 186,3 & 197 & 146,4 & 289,9 & 295,2 & 320,6 & 313,7 & 285,1 & 238,9 & 220,6 \\
\hline $\begin{array}{l}\text { Acid. c/ vít/100.000 } \\
\text { habitantes }\end{array}$ & 277 & 341,8 & 378 & 338,2 & 404,9 & 330,7 & 763,8 & 889,3 & 1134,2 & 1229,4 & 1229,2 & 1117,5 & 1009,5 \\
\hline $\begin{array}{l}\text { Vít. fatais / } 10.000 \\
\text { veículos }\end{array}$ & 9,6 & 10,7 & 11,5 & 11,6 & 11,7 & 12,2 & 11,1 & 11,4 & 6,9 & 7,2 & 4,9 & 5 & 3 \\
\hline $\begin{array}{l}\text { Vít. fatais / } 100.000 \\
\text { habitantes }\end{array}$ & 14 & 17,2 & 20,1 & 21 & 24,1 & 27,6 & 29,2 & 34,3 & 24,3 & 28,3 & 21,3 & 23,3 & 13,6 \\
\hline $\begin{array}{l}\text { Vít. não fatais / } 10.000 \\
\text { veículos }\end{array}$ & 243,3 & 282,4 & 272,8 & 240,8 & 249,6 & 207,8 & 439 & 419,4 & 472,1 & 466,3 & 422,5 & 343,3 & 328,4 \\
\hline $\begin{array}{l}\text { Vít. não fatais / } 100.000 \\
\text { habitantes }\end{array}$ & 356,7 & 455,1 & 477,5 & 437,1 & 512,9 & 469,3 & 1156,6 & 1263,5 & 1670,2 & 1827,2 & 1821,8 & 1605,6 & 1502,5 \\
\hline
\end{tabular}

\section{DISCUSSÃO}

O trauma como doença pode ser entendido na figura de um indivíduo, previamente hígido, que é submetido abruptamente a uma agressão eventual e potencialmente prevenível $^{8}$. Atualmente é uma pandemia moderna na qual os AT estão inseridos, constituindo gravíssimo problema de saúde pública mundial ${ }^{9,10,11}$, sendo a segunda causa básica de morte principalmente de jovens até 29 anos e a terceira causa de morte entre a população adulta até 44 anos em todo o mundo ${ }^{12}$.

De acordo com a Organização das Nações Unidas no Brasil, a taxa de mortalidade por AT na América Latina e Caribe aumentou $20 \%$ entre 2000 a 2010, passando de 14,75 para 17,68 pessoas para cada 100.000 habitantes. A taxa de mortalidade por lesões produzidas no trânsito na mesma região foi de 16,1 em 2010, reduzindo para 15,9 mortos para cada 100.000 habitantes em 2013. A meta de redução dos AT entre 2011 e 2020 é de 50\%, o que ainda está distante de ser realidade ${ }^{13}$.

Além do prejuízo dos anos de vida perdidos por morte prematura, há ainda o aumento dos anos de vida vividos com incapacidade causados pelos traumas ${ }^{14}$, uma vez que os AT incapacitam cerca de 50 milhões de pessoas a cada ano ${ }^{12}$, o que demanda um olhar específico para a assistência em saúde e reabilitação dos pacientes incapacitados. As sequelas ocasionadas pelos AT causam impacto na qualidade de vida dos pacientes e sofrimento por produzirem dor crônica, desconforto, rigidez, perda funcional e deformidades diversas, interferindo na realização de atividades físicas e de lazer, o que também causa impacto negativo nas condições de saúde mental dos pacientes ${ }^{15,16,17}$.

A logística inerente ao processo de cura e reabilitação do paciente engloba a grande demanda de traumas, com consequente superlotação do Sistema Único de Saúde e formação de fila de espera por procedimentos cirúrgicos de reconstrução ortopédica com uso de próteses e reparo estético para aqueles indivíduos que sofreram traumas deformadores. Os pacientes traumatizados em AT, por vezes, não são classificados em situação de risco de morte iminente. Assim, esse fluxo de usuários tem seu tratamento adiado ou não realizado, estando expostos às complicações graves com evolução para óbito ou à lesão permanente e deficiência, além da frustração estética associada, configurando um estado de incapacidade transitória ou definitiva ${ }^{18}$.

Por vezes, os serviços de atendimento especializados estão sobrecarregados com pacientes hospitalizados à espera de tratamento. Nesse sentido, é necessário dispensar atenção para a incidência de transtornos mentais em pacientes em longo período de internação, com manifestação de distúrbios de ansiedade, transtornos obsessivo-compulsivos, depressão, insônia, distúrbios alimentares e, menos comum, enxaqueca e dor neurológica, que podem ter sua origem no período póstraumático ou são condições prévias agravadas pelo trauma ${ }^{16}$. A incapacidade retira o indivíduo do mercado de trabalho, tornando-o improdutivo, o que compromete a renda familiar e eleva o custo social ${ }^{18}$.

O Brasil, por exemplo, é um dos países com maior ocorrência de AT no mundo, com grande efeito sobre os gastos públicos em decorrência do aumento dos atendimentos pré-hospitalares, da assistência médico-hospitalar, da reabilitação, da remoção ou translado da vítima, do dano permanente ou temporário, da população economicamente ativa, dos anos perdidos devido à incapacidade e dos gastos previdenciários. Em 2005, o impacto econômico estimado dos acidentes representou cerca de 6,5 bilhões de reais, equivalente a 1,2\% do Produto Interno Bruto brasileiro no ano ${ }^{10,19,20,21}$.

Lima et al. (2015) afirmam que: os acidentes no trânsito representam um gasto público de R\$ 230 milhões ao ano". Segundo os autores, esse valor foi destinado à assistência de 
cerca de 170 mil vítimas hospitalizadas em serviços conveniados ao Sistema Único de Saúde, em 2013. De acordo com a Previdência Social ${ }^{22}$, em 2013, cerca de 1 milhão de benefícios pagos pelo Instituto Nacional do Seguro Social (INSS) são destinados a vítimas de AT, o que representou despesa superior a 12 bilhões para os cofres do INSS.

A Política Nacional de Redução da Morbimortalidade por Acidentes e Violências prevê em suas diretrizes a necessidade de estruturar e organizar a rede de serviços do SUS, para que ocorra articulação entre os setores da saúde, jurídico e de segurança com a finalidade de acolher e prestar assistência interdisciplinar e intersetorial às vítimas de AT. Assim, a readaptação do paciente ao convívio social tem relação intima com a existência de sequelas físicas e psicológicas, adaptação dos espaços domésticos e urbanos à nova necessidade desses indivíduos, além de incentivo às instituições empregadoras para que contratem essas pessoas, minimizando o custo da assistência prestada e a carga emocional dos pacientes após o trauma ${ }^{23}$

O advento do Complexo Hidrelétrico do Madeira impulsionou o crescimento populacional do estado de Rondônia e da capital Porto Velho, o que resultou em aumento da frota e do número de AT. O incremento populacional trouxe consigo consequências sobre a organização urbana vigente, forçando a ocorrência de alterações demográficas de modo acelerado e sem possibilidade de estabelecer infraestrutura apropriada que comportasse tais mudanças simultaneamente ao processo de transformação.

Martíns et al. (2013) argumentam que o aumento da frota de motocicletas é observado mundialmente, sendo que a posse desse tipo de veículo varia de $70 \%$ a $26 \%$ entre os estados do Brasil, o que é resultado da diferença da infraestrutura de transporte público instalada entre as localidades. Nos grandes centros como São Paulo, Rio de Janeiro, Minas Gerais e Rio Grande do Sul, os autores observaram que há maior utilização de modalidades de transportes públicos como trens, metrôs e ônibus, o que reduz o número de AT e a taxa de mortalidade em relação aos pequenos centros.

O transporte público em Rondônia e em Porto Velho é típico de pequenos centros, onde há disponibilidade apenas de ônibus como meio de transporte coletivo. Por haver poucas opções de transporte público, uma parcela da população prefere adquirir um veículo próprio. Para Bacchieri e Barros (2011) Martíns et al (2013) Nunes e Nascimento (2012), os motociclistas são as principais vítimas de AT, fato que é verificado no contexto regional, devido à alta incidência de AT com motocicletas.

Para Almeida et al. (2013), os acidentes que envolvem motocicletas têm alta relação com óbitos. Essa modalidade de veículo se torna atrativa para a população que detém condições de adquiri-la por ter menor custo e baixo consumo de combustível por quilômetro rodado em relação aos automóveis, uma vez que essa parcela da população pode lançar mão de outros meios de transporte para não depender do transporte coletivo exclusivamente.

A possibilidade de utilização desse tipo veículo para o trabalho e o aumento da produtividade aliado à economia de tempo em virtude do errôneo entendimento de que as motocicletas podem transitar entre os carros de passeio nas vias públicas também é um dos fatores que impulsionam a utilização das motocicletas. Somado a isso, está o fato de que esse veículo passa a ser o principal meio de transporte familiar, condicionando os condutores às infrações das leis de trânsito quando transitam com mais de uma pessoa como passageiro ou criança com idade inferior a sete anos sem uso de equipamento de proteção adequado, em condições que as deixam expostas a lesões graves quando da ocorrência de AT.

Ademais, é preciso observar a infraestrutura implantada nas vias públicas. Almeida et al. (2013, p. 727) argumenta que: "a estrutura das vias como sinalização e iluminação, o dia da semana e o horário da ocorrência estão relacionados à gravidade dos acidentes de trânsito". Assim, a análise de fatores que são inerentes ao desenvolvimento regional desorganizado e que têm fundamental participação nos AT são numerosos e estão vinculados entre si, impossibilitando a visão focalizada em apenas alguns componentes.

O sexo masculino é o gênero mais observado em relação aos AT no estado e na capital, dado que foi observado também em outros estudos ${ }^{1,3,24,25,26,27}$. Almeida et al. (2013) propõem que ações de promoção e prevenção aos AT devem ser concentradas nos indivíduos do sexo masculino.

Quanto à categoria habilitação dos condutores, houve alta porcentagem de inabilitados tanto no estado como na capital. A isso podemos inferir relação com o alto custo dos centros de formação de condutores e do processo de renovação da habilitação, chamado de reciclagem, atuando como um fator que condiciona a população com menor poder aquisitivo a não realizar a reciclagem, o que os torna inabilitados a conduzir veículos. Por outro lado, em determinadas ocasiões, a compra e venda informal de veículos pode ser realizada por pessoas inabilitadas, o que evidencia uma lacuna difícil de combater, uma vez que não há regulamentação para esse tipo de negociação, não necessitando portar Carteira Nacional de Habilitação para finalizar a compra. Esse documento só será requerido caso haja a intenção de formalizar a transferência de propriedade de veículo junto ao DETRAN.

Há também, em menor número, a existência de menores de idade condutores de veículos. É necessária atenção especial para esta faixa etária, tendo em vista que existem comportamentos mais permissivos em relação aos condutores habilitados, culminando com a mistura de imperícia, excesso de velocidade e consumo de bebida alcoólica ${ }^{28,29}$.

É importante, ainda, alertar para a negligência cometida por adultos que permitem e, por vezes, incentivam e ensinam 
menores de idade a conduzir veículos. Em estudo realizado por Andrade et al. (2003), houve predominância do sexo masculino aprendendo a dirigir antes dos 18 anos, sendo que familiares, especialmente o pai $(60,7 \%)$, foram os principais responsáveis pelo ensino da direção de automóvel. Tal atitude é agravada quando há consumo concomitante de álcool, pois aumenta o risco de AT tanto para motoristas como para pedestres ${ }^{26}$.

A "Lei Seca" é outro fator importante a ser considerado como tentativa de redução dos altos índices de AT. Segundo Campos et al. (2013), o fator bebida alcóolica relacionado à direção fez que diversos países desenvolvidos adotassem medidas para reduzir a morbimortalidade no trânsito relacionada a esse fator. Houve redução das colisões de trânsito com a adoção de medidas preventivas como a checagem de sobriedade realizada através do etilômetro, assim como a suspensão da habilitação para aqueles que apresentavam índice de alcoolemia acima do limite legal.

No Brasil, ela era considerada ineficaz ou insuficiente, já que os motoristas dirigiam tendo feito uso de álcool em níveis até então permitidos ou superiores ${ }^{1,26,29,30}$. Entretanto, a Lei 12.760, que foi sancionada em dezembro de 2012 altera o Art. 276 que passa a vigorar prevendo que qualquer concentração de álcool por litro de sangue ou por litro de ar alveolar sujeitaria o condutor às penalidades previstas pelo Art. 165 .

Além disso, conforme o Art. 277, é estabelecido que o condutor envolvido em AT ou que for alvo de fiscalização poderá ser submetido a teste, exame clínico, perícia ou outro procedimento que, em acordo com o Conselho Nacional de Trânsito - CONTRAN, certifique indício de alcoolemia ${ }^{31}$. Em janeiro de 2013, o CONTRAN, por meio da Resolução 432, define que: "a fiscalização do consumo, pelos condutores de veículos automotores, de bebidas alcoólicas e de outras substâncias psicoativas que determinem dependência deve ser procedimento operacional rotineiro dos órgãos de trânsito".

A "Lei Seca" já havia adicionado restrições às propagandas de bebidas alcoólicas, obrigando os fabricantes e estabelecimentos comerciais em que se vendem bebidas alcoólicas a estampar avisos informando que o ato de dirigir sob a influência de álcool constitui crime ${ }^{32}$. A mesma resolução também dispõe sobre a obrigatoriedade da realização do exame de alcoolemia para as vítimas fatais de $\mathrm{AT}^{33}$.

Ademais, as taxas de óbitos no trânsito alcançaram índices alarmantes, o que torna evidente a deficiência das políticas públicas em educação no trânsito, a ineficiência da gestão, a manutenção, a sinalização e a vigilância. Porém, observouse que, após a alteração do Art. 276 do Código de Trânsito Brasileiro, em dezembro de 2012, como aponta Malta et al. (2014), houve intensificação da fiscalização e maior punição de condutores que misturam consumo de bebidas alcoólicas e direção.

Isso é comprovado pelo número de autuações dispensadas e prisões decretadas a condutores flagrados sob efeito de bebidas alcoólicas, como afirmam Lima et al. (2015). Segundo os autores, 6.173 motoristas foram autuados por dirigir sob o uso de álcool. Verificou-se que essa medida trouxe impacto positivo sobre o número de vítimas fatais no trânsito, com redução de $20,8 \%$ em Rondônia e 50,8\% em Porto Velho, entre 2012 e 2013. Já a redução sobre o número de vítimas não fatais foi $4,9 \%$ e $8,2 \%$ respectivamente.

A fim de reduzir infrações de trânsito, políticas públicas que visam ao aperfeiçoamento da formação dos condutores e diminuição dos custos são essenciais. A reciclagem dos condutores deve ocorrer com frequência, com revisão das Leis de Trânsito, tendo em vista que o costume de realizar determinadas ações imprudentes torna-se corriqueiro, substituindo o agir correto pela improvisação, o que leva à infração. Somado a isso, há o excesso de velocidade e o consumo de bebida alcoólica que, juntos, resultam no aumento dos AT. No entanto, a educação em trânsito é um aspecto que precisa ser incentivado e discutido para aprimorar o cenário atual dos AT, com estímulo do uso dos itens de segurança.

Lima et al. (2015), em seu estudo, apresentam as infrações que mais foram cometidas em Porto Velho, no ano de 2013: conduzir veículo que não esteja registrado, ou devidamente licenciado (7.135); dirigir veículo sem possuir $\mathrm{CNH}$ ou permissão para dirigir (5.337); conduzir veículo sem os documentos de porte obrigatório referidos no CTB (5.324); dirigir o veículo utilizando-se telefone celular ou fones nos ouvidos conectados à aparelhagem sonora (2.522); avançar sinal vermelho do semáforo ou parada obrigatória (2.204); deixar o condutor de usar o cinto de segurança (1.602); permitir posse/condução do veículo a pessoa sem CNH ou PPD (1.072) e dirigir sob influência de substância entorpecente que determine dependência física/ psíquica (957). Tais infrações também foram observadas nos anos anteriores, o que revela o desrespeito em relação às leis de trânsito.

O planejamento de ações que visam à prevenção de AT deve estar pautado na educação, na conscientização dos condutores sobre os perigos da combinação álcool e direção, na importância do uso de itens de segurança, além de iluminação e sinalização adequada das vias públicas ${ }^{23,27,34}$.

Medidas como reduzir os postos autorizados de venda de bebidas alcoólicas ou aumento dos impostos sobre essas mercadorias podem auxiliar na diminuição do consumo, porém são ações pouco efetivas e incapazes de transformação de hábitos e costumes. O principal objetivo a ser alcançado é o uso correto dos equipamentos de segurança e o trânsito dentro dos limites de velocidade indicados em cada via.

Visando à educação da população, o DETRAN-RO, por meio da Semana Nacional de Trânsito, busca promover blitz educativas diurnas e noturnas, com auxílio da sociedade civil organizada para mobilizar os cidadãos a respeitarem as Leis de Trânsito. Também há o projeto "Anjos no Trânsito", que foi realizado 
em dois módulos na Escola Estadual Ensino Médio Major Guapindaia, em Porto Velho. Essa atividade teve o objetivo de permitir a criação de técnicas para reflexão e dinâmicas em grupos sobre a temática do trânsito, envolvendo problemáticas diárias e capacitação por meio da formação teórico-técnica para formação da carteira nacional de habilitação ${ }^{35}$.

Outra atividade social desenvolvida é a realização do "Projeto Bi-bip", que acontece nas escolas públicas voltadas para crianças de 7 a 11 anos do Ensino Fundamental ${ }^{36}$. A semana de comemorações ainda promove caminhadas, exposição de materiais educativos no shopping da capital, brincadeiras e testes de bafômetro para os visitantes, com o objetivo de alertar o cidadão de sua responsabilidade no trânsito ${ }^{37}$.

Há poucas publicações nos últimos anos sobre a temática dos AT e os aspectos que lhe são pertinentes. Há escassos estudos que correlacionaram diretamente a redução do número de AT com a intensificação e o maior rigor instituídos pela revisão da "Lei Seca" em 2012.

A educação é o passo inicial em busca da mudança dos hábitos da população, condição necessária para que o número de AT com vítimas fatais e não fatais diminua. A conscientização é um dos meios mais eficazes para que haja formação de opinião, mas é necessário que o poder público atue ativamente na fiscalização e que a sociedade não se silencie diante da alta morbimortalidade que os AT acarretam.

A educação infantil nas escolas desde os primórdios é essencial para que as crianças conheçam a importância de exercerem sua cidadania de modo consciente. Ademais, crianças poderão atuar como verdadeiros "fiscais mirins", já que serão capazes de compreender atitudes certas e erradas por meio da observação da conduta dos adultos, sendo capazes de julgamento moral, ético e cidadão sobre adultos infratores, imputando carga psicológica sobre pais e familiares, sensibilizando-os a agir de modo correto.

O manejo das vítimas não fatais em processo de reabilitação demanda atenção humanizada, processo que tem início na assistência à saúde de qualidade prestada no ambiente hospitalar, estendendo-se à promoção de reinserção do indivíduo no espaço social e à adaptação do ambiente urbano às necessidades emergentes. A educação atua, ainda, visando à prevenção da recorrência de acidentes com indivíduos já vitimados. A conscientização da população constitui, portanto, fator indispensável para que os comportamentos infratores sejam expostos e debatidos, a fim de resgatar os conceitos de cidadania e ética no trânsito para obter mudanças dos hábitos e costumes.

\section{REFERÊNCIAS}

1. Bacchieri G, Barros AJD. Acidentes de trânsito no Brasil de 1998 a 2010 muitas mudanças e poucos resultados. Rev. Saúde Pública. 2011; 45(5): 949-63. doi: http://dx.doi.org/10.1590/S0034-89102011005000069.

2. Marín L, Queiroz MS. A atualidade dos acidentes de trânsito na era da velocidade: uma visão geral. Cad. Saúde Pública. 2000 Jan-Mar; 16(1): 7-21. doi http://dx.doi.org/10.1590/S0102-311X2000000100002.

3. Barros AJD, Amaral RL, Oliveira MSB, Lima SC, Gonçalves EV. Acidentes de trânsito com vítimas: sub-registro, caracterização e letalidade. Cad. Saúde Pública. 2003 Jul-Ago; 19(4): 979-986. doi: http://dx.doi.org/10.1590/S0102$311 \times 2003000400021$

4. Ministério da Saúde (BR). Óbitos por Causas Externas. Brasília: DATASUS 2013.

5. Waiselfisz JJ. Mapa da Violência 2013: acidentes de trânsito e motocicletas. Rio de Janeiro: Centro Brasileiro de Estudos Latino-Americanos, Faculdade Latino-Americana de Ciências Sociais; 2013.

6. Ministério da Saúde (BR). Informações de Saúde. base de dados na internet. Brasília: Ministério da Saúde; 2011.

7. DEPARTAMENTO NACIONAL DE TRÂNSITO. Relatórios estatísticos da frota de veículos segundo ano de referência [Internet]. Brasília: Ministério das Cidades; 2015. [acesso 2015 dezembro 28] Disponível em: http://www.denatran.gov.br/ index.php/estatistica/249-frota-2013.

8. Rasslan S, Birolini D. O trauma como modelo de doença. Rev. Col. Bras. Cir. 1998 Sept-Oct.; 25(5): 3.

9. Cavalcante FG, Morita PA, Haddad SR. Sequelas invisíveis dos acidentes de trânsito: o transtorno de estresse pós-traumático como problema de saúde pública. Ciênc saúde coletiva. 2009; 14(5): 1763-1772. doi: http://dx.doi. org/10.1590/S1413-81232009000500017.
10. Nunes MN, Nascimento LFC. Análise espacial de óbitos por acidentes de trânsito, antes e após a Lei Seca, nas microrregiões do estado de São Paulo. Rev Assoc Med Bras. 2012 Nov-Dec; 58(6): 685-690. doi: http://dx.doi.org/10.1590/ S0104-42302012000600013.

11. Morais OLd Neto, Silva MMA, Lima CMd, Malta DC, Silva JBd Jr. Projeto vida no trânsito; avaliação das ações em cinco capitais brasileiras, 2011-2012. Epidemiol. Serv. Saúde. 2013 jul-set; 22(3): 373-382. doi: 10.5123/S167949742013000300002.

12. World Health Organization. World Health Day: Road safety is no accident! [Internet].Genebra: WHO; 2004 [acesso 2015 setembro 04]. Disponível em: http://www.who.int/mediacentre/news/releases/2004/pr24/en/

13. Nações Unidas no Brasil. Elevado número de mortes no trânsito na América Latina será tema de Conferência da ONU em Brasília. [Internet].Rio de Janeiro: ONUBR; 2015 [acesso 2016 novembro 02]. Disponível em: https:// nacoesunidas.org/elevado-numero-de-mortes-no-transito-na-america-latinasera-tema-de-conferencia-da-onu-em-brasilia/.

14. Schramm JMA, Oliveira AFd, Leite IdC, Valente JG, Gadelha ÂMJ, Portela MC, et al. Transição epidemiológica e o estudo de carga de doença no Brasil. Ciênc saúde coletiva. 2004; 9(4): 897-908.

15. Olofsson E, Bunketorp O, Andersson AL. Children at risk of residual physical problems after public road traffic injuries - A 1-year follow-up study. Injury. 2012 Jan; 43(1): 84-90.

16. Berecki-Gisolf J, Collie A, Hassani-Mahmooei B, McClure R. Use of antidepressant medication after road traffic injury. Injury. 2015 Feb; 46(7): 1250-1256. doi: 10.1016/j.injury.2015.02.023.

17. Xavier EP. Orientações educativas ao acidentado no trânsito no contexto da hospitalização-reabilitação [Dissertação]. Fortaleza (CE): Universidade de Fortaleza; 2006. 
18. Machado CR. Proposição de modelo de atendimento ao trauma ortopédico gerenciado pelo Instituto Nacional de Traumatologia e Ortopedia [Dissertação]. Rio de Janeiro (RJ): Fundação Oswaldo Cruz; 2009.

19. Trevisol DJ, Bohm RL, Vinholes DB. Perfil epidemiologico dos pacientes vítimas de acidentes de trânsito atendidos no serviço de emergência do Hospital Nossa Senhora da Conceição em Tubarão, Santa Catarina. Scientia Medica. 2012; 22(3): 148-152.

20. BRASIL. Impactos sociais e econômicos dos acidentes de trânsito nas rodovias brasileiras: relatório executivo. Brasília: Instituto de Pesquisa Econômica Aplicada/ Departamento Nacional de Trânsito/ Associação Nacional dos Transportes Públicos; 2006.

21. Deslandes SF, Silva CMFP. Análise da morbidade hospitalar por acidentes de trânsito em hospitais públicos do Rio de Janeiro, RJ, Brasil. Rev. Saúde Pública. 2000 Aug; 34(4): 367-72.

22. Previdência Social. CNPS: acidentes de trânsito representam uma despesa de 12 bi para a previdência [Internet]. Brasília: Previdência Social; 2013 [acesso 2016 Out 30.Disponível em: http://www.previdencia.gov.br/2013/12/cnpsacidentes-de-transito-representam-uma-despesa-de-12-bi-para-a-previdencia/

23. BRASIL. Política nacional de redução da morbimortaldade por acidentes e violências. Brasília: Ministério da Saúde; 2005.

24. Martins ET, Boing AF, Peres MA. Mortalidade por acidentes de motocicleta no Brasil: análise de tendência temporal, 1996-2009. Rev Saúde Pública. 2013 Oct 47(5): 931-41. doi: http://dx.doi.org/10.1590/S0034-8910.2013047004227.

25. Ladeira RM, Barreto SM. Fatores associados ao uso de serviço de atenção pré-hospitalar por vítimas de acidentes de trânsito. Cad. Saúde Pública. $2008 \mathrm{fev}$; 2(24): 287-294. doi: http://dx.doi.org/10.1590/S0102-311X2008000200007.

26.Campos VR, Salgado RS, Rocha MC. Bafômetro positivo: correlatos do comportamento de beber e dirigir na cidade de Belo Horizonte, Minas Gerais, Brasil. Cad. Saúde Pública. 2013 Jan; 29(1): 51-61. doi: http://dx.doi. org/10.1590/S0102-311X2013000100007.

27. Almeida RLFd, Bezerra JG Filho, Braga JU, Magalhães FB, Maceda MCM Silva KA. Via, homem e veículo: fatores de risco associados à gravidade dos acidentes de trânsito. Rev Saúde Pública. 2013; 47(4): 718-731. doi: http:// dx.doi.org/10.1590/S0034-8910.2013047003657.

28. Andrade SMd, Soares DA, Braga GP, Moreira JH, Botelho FMN Comportamentos de risco para acidentes de trânsito: um inquérito entre estudantes de medicina na região sul do Brasil. Rev Assoc Med Bras. 2003; 49(4): 439-44. doi: http://dx.doi.org/10.1590/S0104-42302003000400038.

29. De-Boni R, Leukefeld C, Pechansky F. Young people's blood alcohol concentration and the alcohol consumption in city law, Brazil. Rev Saúde Pública. 2008 Dec; 42(6): 1001-4. doi: http://dx.doi.org/10.1590/S0034-

\section{4.}

30. Duailibi S, Pinsky I, Laranjeira R. Prevalência do beber e dirigir em Diadema, estado de São Paulo. Rev Saúde Pública. 2007; 41(6): p. 1058-61. doi: http:// dx.doi.org/10.1590/S0034-89102006005000045.

31. Brasil. Lei no 12.760 , de 20 de dezembro de 2012. Altera a Lei no 9.503 , de 23 de setembro de 1997, que institui o Código de Trânsito Brasileiro. Diário Oficial [da] República Federativa do Brasil. 2012 Dez 21; Seção 1.

32. Brasil. Lei no 11.705 , de 19 de junho de 2008. Altera a Lei no 9.503 , de 23 de setembro de 1997, que 'institui o Código de Trânsito Brasileiro', e a Lei no 9.294 , de 15 de julho de 1996, que dispõe sobre as restrições ao uso e à propaganda de produtos fumígeros, bebidas alcoólicas, medicamentos, terapias e defensivos agrícolas, nos termos do $\S 40$ do art. 220 da Constituição Federal, para inibir o consumo de bebida alcoólica por condutor de veículo automotor, e dá outras providências. Diário Oficial [da] República Federativa do Brasil. 2008 Jun 20; Seção 1.

33. Brasil. Conselho Nacional de Trânsito. Resolução no 432, de 23 de janeiro de 2013. Dispõe sobre os procedimentos a serem adotados pelas autoridades de trânsito e seus agentes na fiscalização do consumo de álcool ou de outra substância psicoativa que determine dependência, para aplicação do disposto nos arts. 165, 276, 277 e 306 da Lei no 9.503, de 23 de setembro de 1997 Código de Trânsito Brasileiro (CTB). Diário Oficial [da] República Federativa do Brasil. 2013 Jan 29. Seção 1.

34. Lima TL, Souza MES, Barbosa XC, Souza MSS Junior. Violência no trânsito uma abordagem da problemática na cidade de Porto Velho. Zona de Impacto. 2015 Jan-Jun; 1: 97-112.

35. DETRAN-RO. Notícias Detran inicia projeto " Anjos no Trânsito" na escola estadual Major Guapindaia em Porto Velho [Internet]. Porto Velho: DETRANRO; 2016 [acesso 2016 outubro 31. Disponível em: https://www.detran.ro.gov. br/2016/09/detran-inicia-projeto-anjos-no-transito-na-escola-estadual-majorguapindaia-em-porto-velho/.

36. DETRAN-RO. DETRAN comemora semana de trânsito em escolas públicas [Internet]. Porto Velho: DETRAN-RO; 2012 [acesso 2016 outubro 31]. Disponível em: https://www.detran.ro.gov.br/2012/09/detran-comemora-semana-detransito-em-escolas-publicas/.

37. DETRAN-RO. Detran-RO leva semana nacional do trãnsito para shopping na capital [Internet]. Porto Velho: DETRAN-RO; 2016 [acesso 2016 outubro 31]. Disponível em: https://www.detran.ro.gov.br/2016/09/detran-ro-leva-semananacional-do-transito-para-shopping-na-capital/.

38. Malta DC, Berna RTI, Silva MMAd, Claro RM, Silva JB Júnior, Reis AAC. Consumo de bebidas alcoólicas e direção de veículos, balanço da Lei Seca, Brasil, 2007 a 2013. Rev Saúde Pública. 2014 Aug; 48(4): 692-696. doi: http:// dx.doi.org/10.1590/S0034-8910.2014048005633. 